\title{
Thermovision in studies on passenger car fire development
}

\author{
by A. Szajewska*
}

*The Main School of Fire Service,01-629 Słowackiego Str. 54/54,Warsaw, Poland, ania.szajewska@ gmail.com

\begin{abstract}
The paper presents the results of experiments on the car fire development. The temperature was measured by a thermal camera and thermocouples. The experiments aimed at determining the usefulness of a thermal camera for measuring the temperature in the fire environment as well as verifying its readings. Determining the emissivity coefficient constituted the main problem. Irreversible changes in the surface occur during the combustion process. There are chemical reactions; the varnish peels and falls off. Smoke applies a layer of soot. In higher temperature the layer of soot disappears. Such processes influence on the emissivity coefficient changing and camera readings.
\end{abstract}

\section{Introduction}

Fire Service in Poland and all over the world use thermovision in rescue and fire prevention actions [1]. Thermal cameras has become standard equipment of the Fire Service Units. The producers have developed special thermal cameras adjusted for work in fire environment. This kind of cameras is characterized by simplicity in usage. The simplicity is essential for firefighters who operate the camera by hand dressed in a heavy glove. The cameras are in casing protecting from humidity, shocks, brief exposure tohigh temperatures. They arecompact, lightweight andhandy.

Thermal cameras included in the equipment of the State Fire Service in Poland are used mainly during putting out structure fires. But such cameras are used in wildfires as well. The cameras are a very useful tool to carry such actions. The observation of the object and the temperature can be carried out from a safe distance location. Thermal cameras used in studies carried out in the Main School of Fire Service in Warsaw were intended for observing and measuring the temperature in passenger car fire tests [5]. The process of car combustion is usually accompanied by bursts ofcylinders, shock absorbers, elements of the brake system, tires, batteries, etc. Loose elements may hurt people standing nearby. In case of cars powered by gas (LPG, CNG, H2) it must be remembered that safety valves may not work properly and the gas tank may burst out. In such case,debrisfiring rangecan reach300 m. The cameraallows carrying the researcheswhile maintainingsafety requirements.

In Poland there are about 20 car fires per day, including 2 arsons. The researchesaim atunderstandingthe process of fire development and dangers that rescuersand bystanders are exposed to. Producers present new technologies and use new materials. It all creates new threats and demands adjusting the extinguishing techniques to new challenges. The knowledge on fire development is essential for not only the rescuers but for the experts as well. Firefighters who prepare the fire expertises for court trials must present the full knowledgeabout the processof car burningunder various conditions, todemonstratethe fire initiation and the cause offire. Researches on car fire developments are carried out in many centers $[2,3,4]$.

\section{The course of the experiment and its results. Measurement of the windscreen temperature}

The vehicleused forthe experiment was a Fiat Punto car. Thermocouples were mounted in specific places inside the car and on its body. The surface temperature was measured by a thermographic system ThermaCAM SC640 (Flir Systems A.B.) as well. A part of the window in right front car door was covered by a thick layer of soot. The remaining part stayed uncovered.

Figure 1 presents a picture of the car which was the object of the experiment. The black windscreenarea covered by soot is visible in the picture. Figure 2 represents the thermogram of the car. The part of windscreen, that was covered by soot, shows higher emissivity. Contrast between the part of the soot-covered and uncovered parts of the car window disappears with the increase of temperature, indicating leveling the emissivity of these areas. 


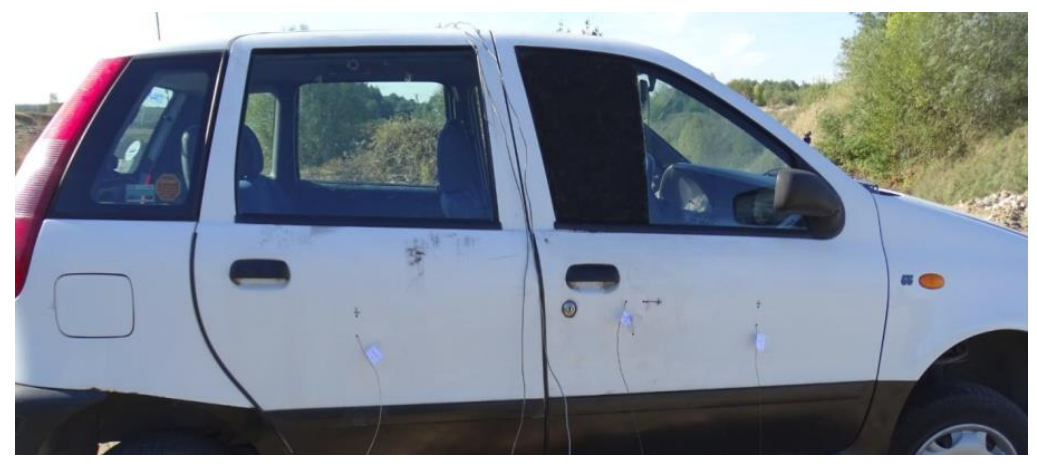

Fig. 1. The object of the experiment
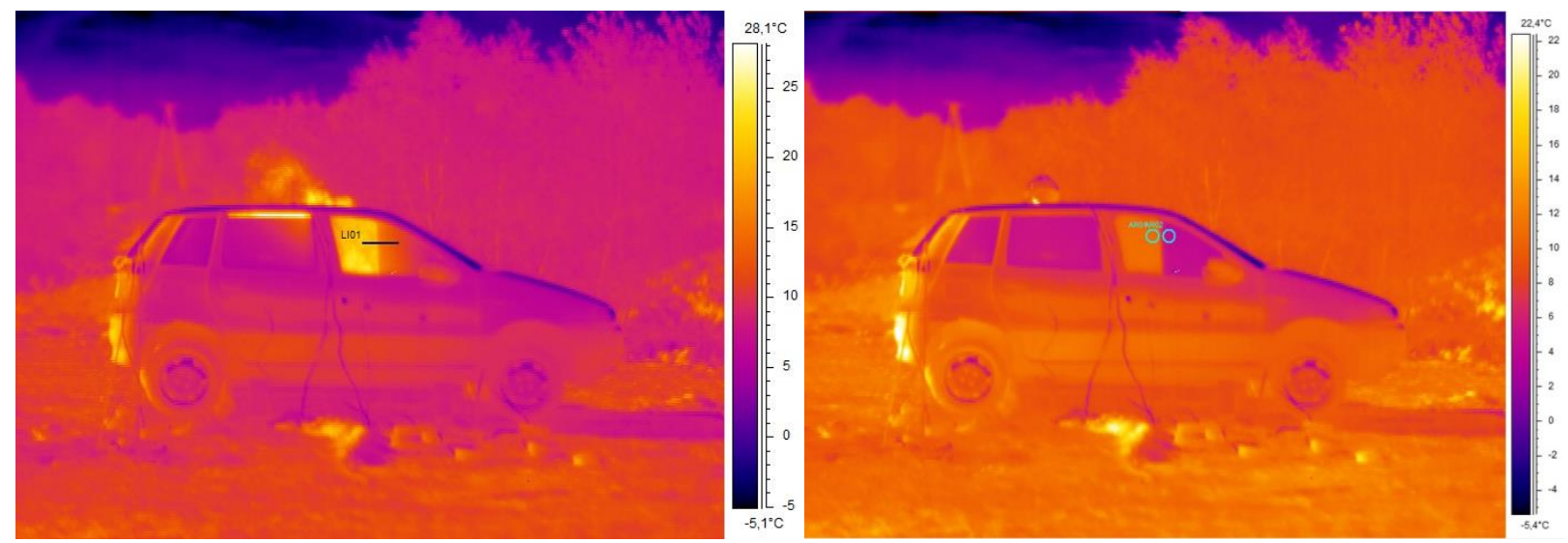

Fig. 2. The thermogram of the car. The measurement profile marked on the window

Thethermogram includes a profile perpendicular to the line separating the parts covered and uncovered by soot. This is the spot where temperature was taken. Figure 3 presents the temperature distribution along the profile. It was assumed that the emissivity coefficient for the glass covered by soot was $\varepsilon=0,96$ and it doesn't change under temperature changes.

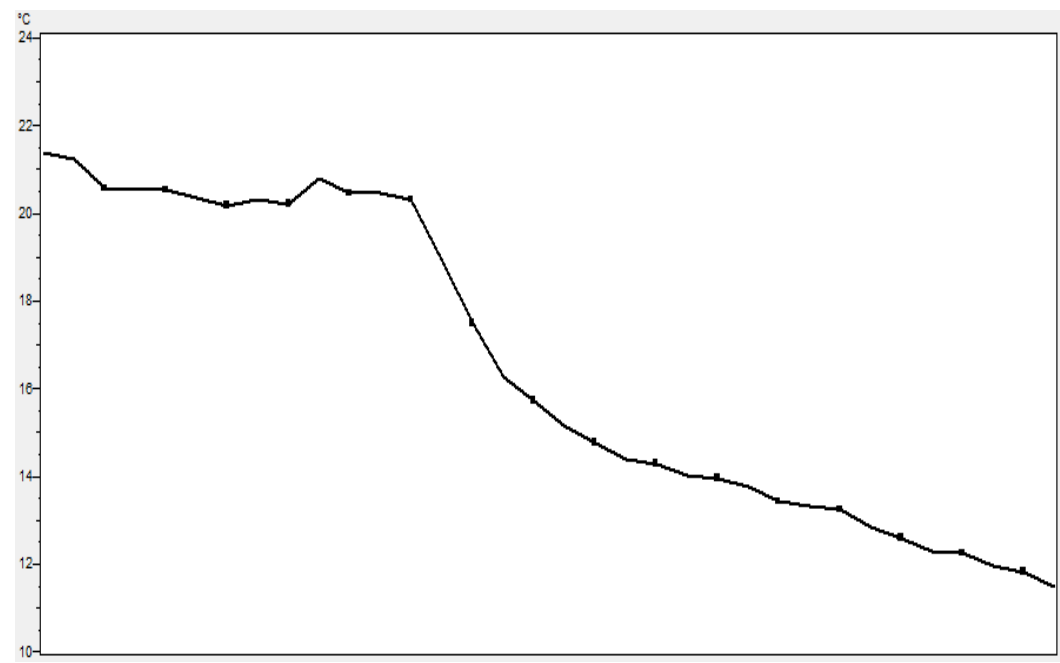

Fig. 3. Temperature distribution along the profile marked in Fig. 2. 


\subsection{1/qirt.2016.166}

The value of the window glass emissivity coefficient during car burning was set using the ThermaCAM Flir system.Two areas of measurement were defined on the line separating the portion of the windscreen covered and uncovered by soot (Fig. 2). The values of emissivity coefficient for the uncovered area was set in relation to the glass covered with soot (as its emissivity coefficient was known). Measurement areas were close to each other, so it can be assumed that their temperatures were the same. Figure 4 presents a graph with the readings.

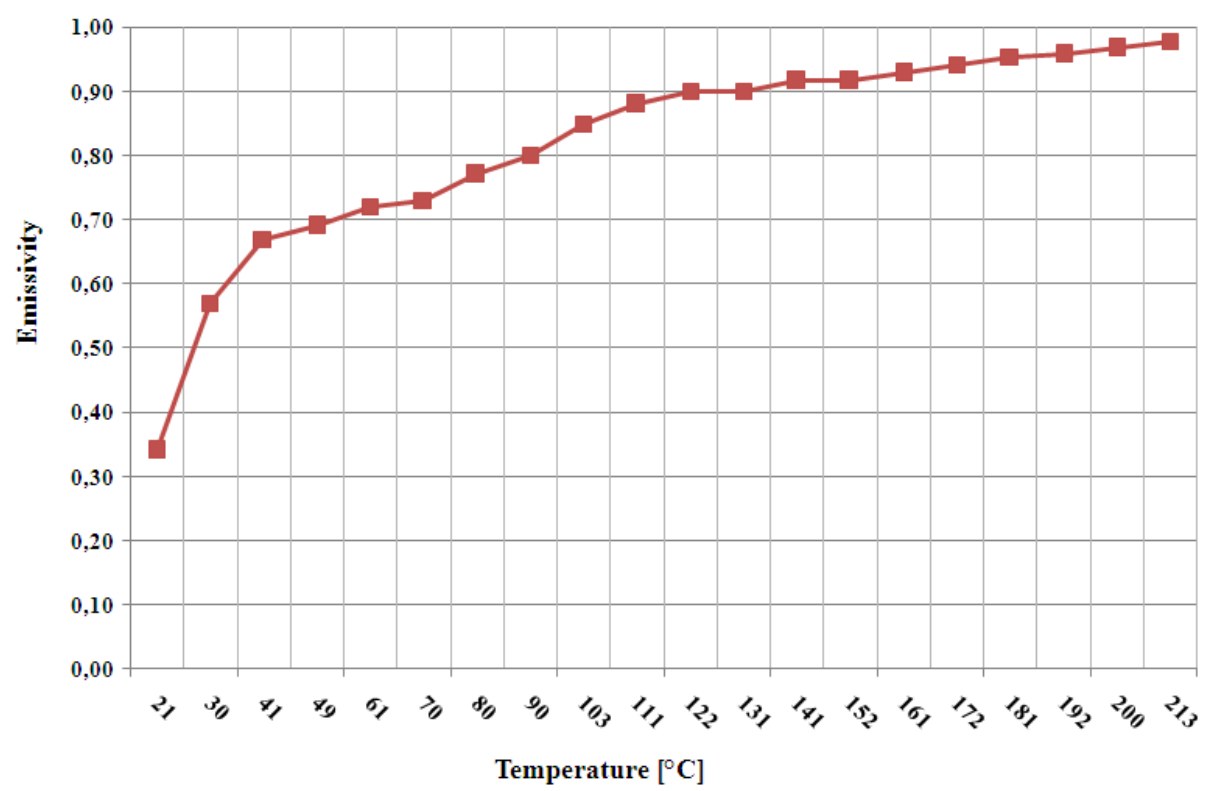

Fig. 4. Dependence of the emissivity coefficient of the glass from the temperature at the first stage of car burning

\section{Measuring the temperature of the car body}

The burning process was initiated from inside creating conditions for rapid fire development. Window on the driver side was open. The window on the passenger side remained not fully closed. There was a rug soaked with petrol (100 ml) left on the driver seat, which was set alight with a torch. The fire developed rapidly. After 1 min $10 \mathrm{~s}$ the glass in left rear window fell out. After $1 \mathrm{~min} 12 \mathrm{~s}$ the front window glass on the passenger side fell apart - it was the window glass were the measurements were taken. A moment prior to the fall out, the camera indicated $215^{\circ} \mathrm{C}$. After $1 \mathrm{~min}$. $17 \mathrm{~s}$ form the moment of fire initiation, the left rear window glass fell out. This ensured free air flow and the vehicle reached the phase of fully developed fire. The temperature in passenger and luggage compartments exceeded $600^{\circ} \mathrm{C}$. Changes on the surface occurred after exceeding the temperature of $200^{\circ} \mathrm{C}$. The varnish got black and then it was carbonized and came off the metal surface after exceeding $300^{\circ} \mathrm{C}$.

The phenomenaoccurringon the surfaceaffects itsemissivity [6]. Comparative measurements taken by a thermocouple were made to set the the emissivity coefficient $\varepsilon$ that should be uploaded to camera software before the car fire experiments. ThermaCAM was used to adjust the distribution of measurements taken by a camera to measurements taken by a thermocouple. The results have been presented in figure 5 . The correlation coefficient equals 0.990 . The determined value of emissivity coefficient $\varepsilon=0.92$. Figure 6 . presents the picture of the experiment object. 


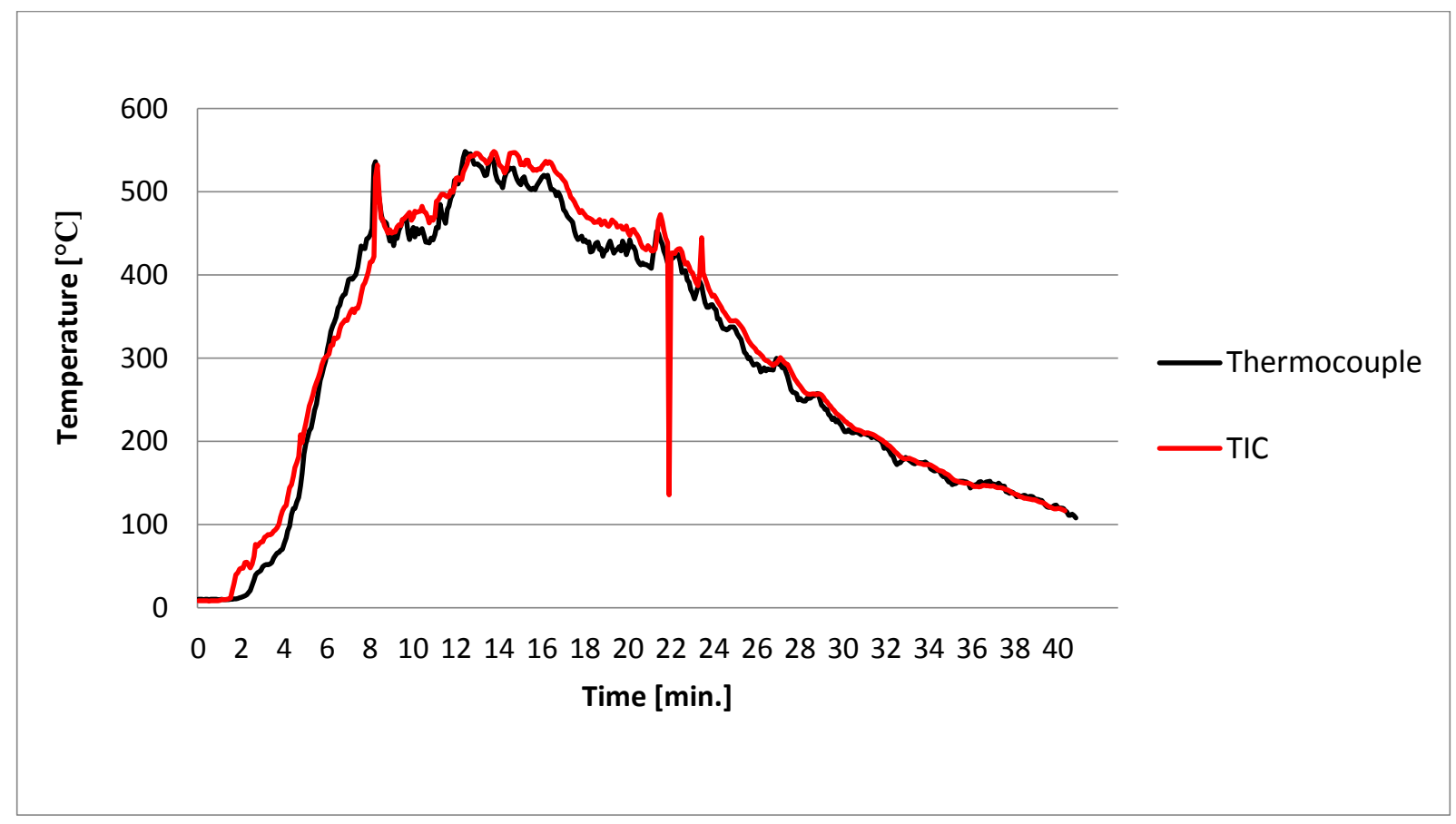

Fig. 5. The courses of temperature measured by a thermal camera and a thermocouple

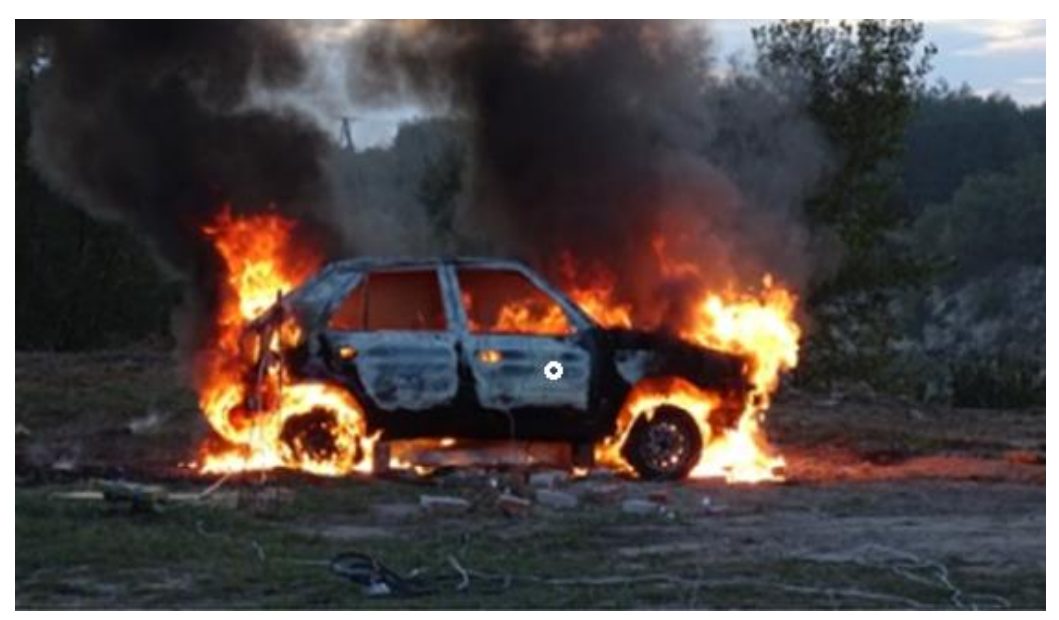

Fig. 6. The car in the final phase of burning. The measurement area is marked by a circle on the car body

During the test, the wind direction was approximately constant. The smoke did not interfere with measuring areas of the camera. The wind was stable with no major outbursts. The average wind speed was about $2 \mathrm{~m} / \mathrm{sec}$. The direction and wind speed are shown in the diagrams in Fig. 7 and Fig. 8. 


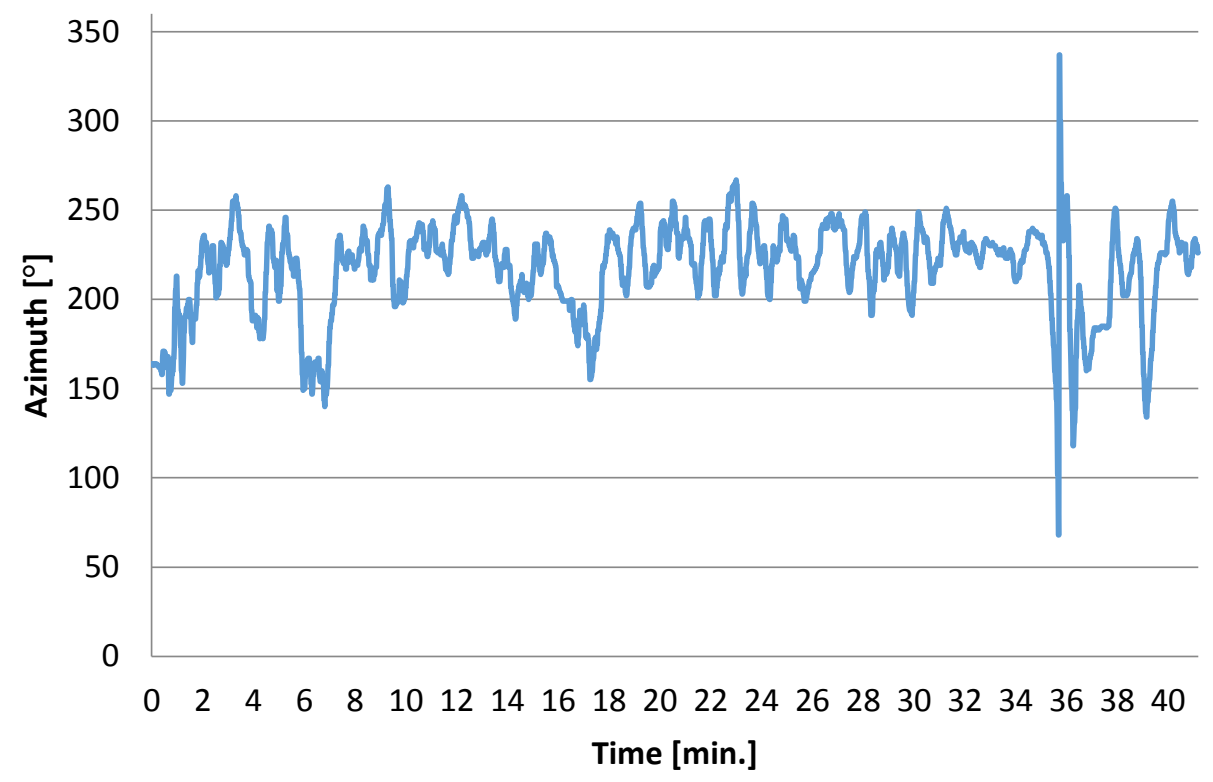

Fig. 7.Wind direction during the test

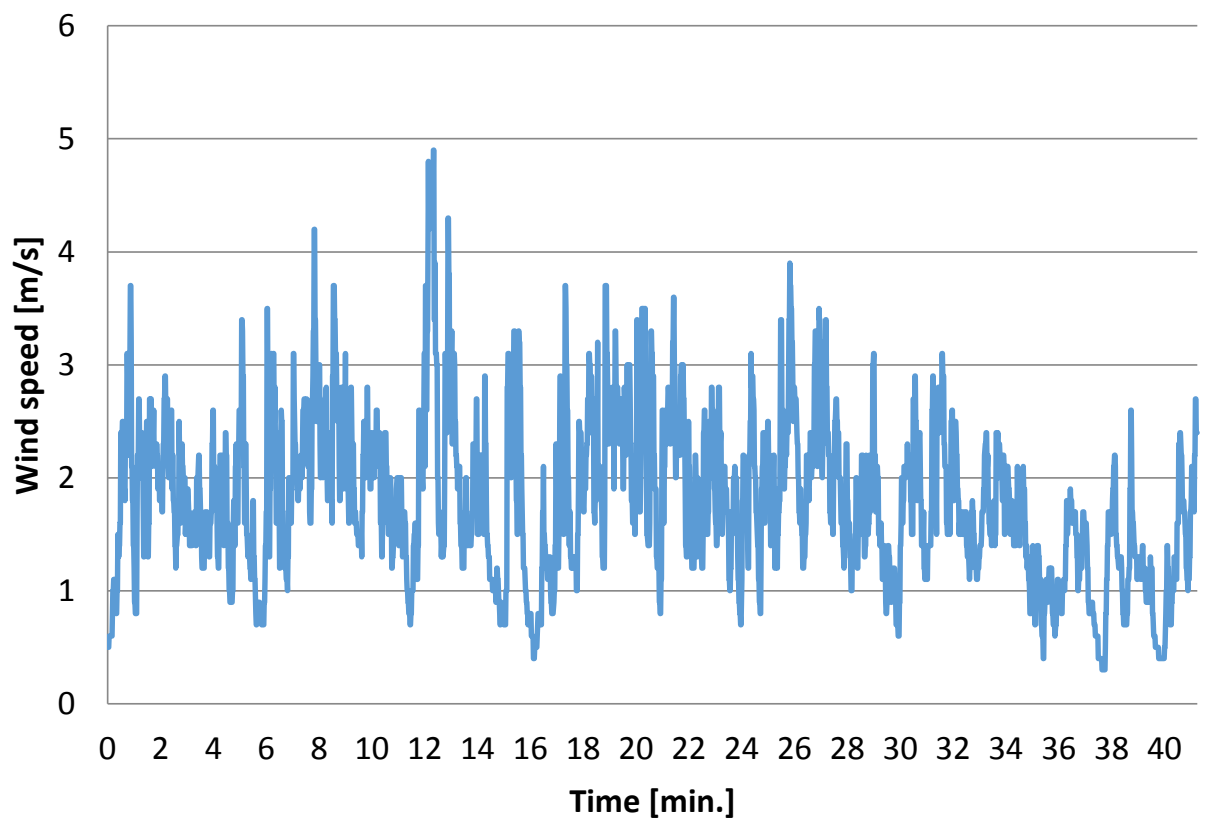

Fig. 8. Wind speed during the test

\section{Conclusions}

Fire is an unpredictable phenomenon. The dynamics of external fire strongly depends on the weather conditions. During this test the atmospheric conditions were stable. Smoke and flames did not obscure the thermal imager view, but only from one side of the car. Under these conditions the indications of thermocouples and infrared camera were approximately compatible. It should be noted that the thermocouple has multisecond inertia of temperature, while the infrared camera does not. Thermocouples have a considerable heat capacity and, therefore, the rapid temperature changes cause time delay in their readings. Thermocouples, which were used in the experiment, were initially at room 


\subsection{1/qirt.2016.166}

temperature, and placed in boiling water indicated $100^{\circ} \mathrm{C}$ after about 10 seconds. Effects associated with thermal inertia cause divergence indications between the infrared camera and the thermocouple.

The test shows that the results of the car body temperature measurements made by an infrared camera may be correct. It should be assumed that the average value of emissivity for complete combustion is $\varepsilon \approx 0.92$. In case of unstable weather conditions the measurement is very difficult. It seems that the the measurement can be carried out only on the windward side. The advantages of taking measurements by an infrared camera are convenience, mobility, operator safety. The camera is located on the fire engine, so it is accessible to firefighters during firefighting operations.

It is much harder to measure the temperature of the glass. The emissivity coefficient of glass changes rapidly during the car burning. In such conditions the camera settings should be constantly changed, which is practically impossible during a fire. The emissivity coefficient stabilizes not before the temperatures reaches $120^{\circ} \mathrm{C}$. The temperature at which the glass ejection can be expected comes with the emissivity coefficient exceeding 0.95 . The camera can provide us with information, at which point we can expect the glass to fall out. This is valuable information from the fire point of view, because the glass falling dramatically increases the dynamics of fire and can cause flashover.

\section{REFERENCES}

[1] Amon F., Hamins A., Bryner N., Rowe J.: "Meaningful performance evaluation conditions for fire service thermal imaging cameras. Fire Safety Journal, vol.43, pp.541-550, 2008.

[2] Bunn T. L., Slavowa S., Robertson M., Crash and burn? Vehicle, collision, and driver factors that influence motor vehicle collision fires. Accident Analysis and Prevention, vol. 47, pp. 140-145, 2012.

[3] Okamoto K., Otake T., Miyamoto H., Honma M., Burning behavior of minivan passenger cars. Fire Safety Journal, vol. 62, pp. 272-280, 2013.

[4] Slimonowa M., Polednak P., Findigs from experimental verification of passenger motor car fires in closed space. Pozarniochrona VSB -TU, Ostrava, 2010, 324-326.

[5] Szajewska A, Świder R. Rybiński J., Determining of a passenger car fire temperature, Measurement Automation Monitoring, Vol. 61, No 6, pp. 275-277, 2015.

[6] Więcek B., De Mey G.: Thermovision in IR. Basics. Termowizja w podczerwieni podstawy, Wydawnictwo PAK, Warszawa 2011. 